\title{
Sex differences in invasive pneumococcal disease and the impact of pneumococcal conjugate vaccination in the Netherlands, 2004 to 2015
}

GHJ Wagenvoort ${ }^{1}$, EAM Sanders ${ }^{23}$, BJ Vlaminckx ${ }^{1}$, HE de Melker ${ }^{2}$, A van der Ende ${ }^{4}$, MJ Knol ${ }^{2}$

1. Department of Medical Microbiology and Immunology, St. Antonius Hospital, Nieuwegein, the Netherlands

2. Centre for Infectious Disease Control Netherlands (CIb), National Institute for Public Health and the Environment (RIVM), Bilthoven, the Netherlands

3. Department of Immunology and Infectious diseases, University Medical Center Utrecht, Wilhelmina Children's Hospital, Utrecht, the Netherlands

4. Department of Medical Microbiology and the Netherlands Reference Laboratory for Bacterial Meningitis, Academic Medical Center, Amsterdam, the Netherlands

Correspondence: Gertjan Wagenvoort (wagenvoort@gmail.com)

Wagenvoort GHJ, Sanders EAM, Vlaminckx BJ, de Melker HE, van der Ende A, Knol MJ. Sex differences in invasive pneumococcal disease and the impact of

pneumococcal conjugate vaccination in the Netherlands, 2004 to 2015. Euro Surveill. 2017;22(10):pii=30481. DOl: http://dx.doi.org/10.2807/1560-7917.

ES.2017.22.10.30481

Article submitted on 08 June 2016 / accepted on 06 September 2016 / published on o9 March 2017

Implementation of pneumococcal conjugate vaccines in the Netherlands (PCV7 in 2006 and PCV10 in 2011) for infants caused a shift in serotypes in invasive pneumococcal disease (IPD). We explored sex differences in serotype-specific IPD incidence before and after vaccine introduction. Incidences in the pre-PCV7 (June 2004-May 2006), post-PCV7 (June 2008-May 2011) and post-PCV10 period (June 2013-May 2015), stratified by age, were compared. Incidence was higher in men for all age groups (overall in men: 16.7, 15.5 and 14.4/100,000 and women: 15.4, 13.6 and 13.9/100,000 pre-PCV7, post-PCV7 and post-PCV10, respectively), except for 20-39 year-olds after $P^{2} V_{7}$ and 40-64 yearolds after PCV10 introduction. After $\mathrm{PCV}_{7}$ and $\mathrm{PCV}_{10}$ introduction, the overall IPD incidence decreased in men aged 20-39 years (from 5.3 pre-PCV 7 to 4.7 and 2.6/100,000 post-PCV7 and post-PCV10, respectively), whereas it showed a temporary increase in women (from 3.9/100,000 pre-PCV7 to 5.0/100,000 post-PCV7 and back to $4.0 / 100,000$ post-PCV10) due to replacement disease. PCV10 herd effects were observed throughout, but in women older than 40 years, a significant increase in non-PCV10 serotype offset a decrease in overall IPD incidence. Ongoing surveillance of IPD incidence by sex is important to evaluate the long-term effects of PCV implementation.

\section{Introduction}

Sex differences play an important role in clinical disease susceptibility and outcome. In infectious diseases, the burden of bacterial, fungal, parasitic and viral disease is generally higher in men than in women [1-3]. However, with the exception of urinary tract infections, sex differences are often neglected in surveillance reports $[4,5]$. Also for Streptococcus pneumoniae, a frequent coloniser of the nasopharynx and cause of severe infections, the observed incidences of pneumococcal pneumonia and invasive pneumococcal disease (IPD) have been higher in men [6-8]. Young children have the highest pneumococcal carriage rates and are the key transmitters of $S$. pneumoniae in the population. However, no systematic age-specific differences in asymptomatic pneumococcal nasopharyngeal carriage rates have been observed between boys and girls [9-11]. Pneumococcal conjugate vaccination (PCV) has led to eradication of vaccine serotype carriage but immediate replacement by non-vaccine serotypes with a modest reduction in overall pneumococcal carriage in children $[12,13]$.

In many countries, extensive IPD surveillance programmes were implemented before and after introduction of PCV in childhood immunisation programmes [14-17]. Although many surveillance reports described the impact of the first licensed 7-valent PCV $\left(\mathrm{PCV}_{7}\right)$ on (serotype-specific) IPD incidences in different age groups [17], only limited data have been reported by sex [18-20]. In the Netherlands, $\mathrm{PCV}_{7}$ has been introduced for infants born after 1 April 2006 (in a 3+1 schedule) with a coverage of $94-95 \%$ since its introduction [21] and has led to a shift from vaccine to nonvaccine serotypes causing IPD ('replacement disease') in all age groups. In children eligible for vaccination, the decline in vaccine serotype IPD was strongest, but overall IPD incidence decreased due to herd protection in most age groups, in particular in persons 65 years and older $[16,17]$.

Differences in the impact of pneumococcal conjugate vaccines between men and women do occur. Hak et al. 


\section{FIGURE 1}

Age-specific incidence of invasive pneumococcal disease in men and women in the pre- and post-PCV periods, the Netherlands, 2004-15 ( $\mathrm{n}=4,303)$

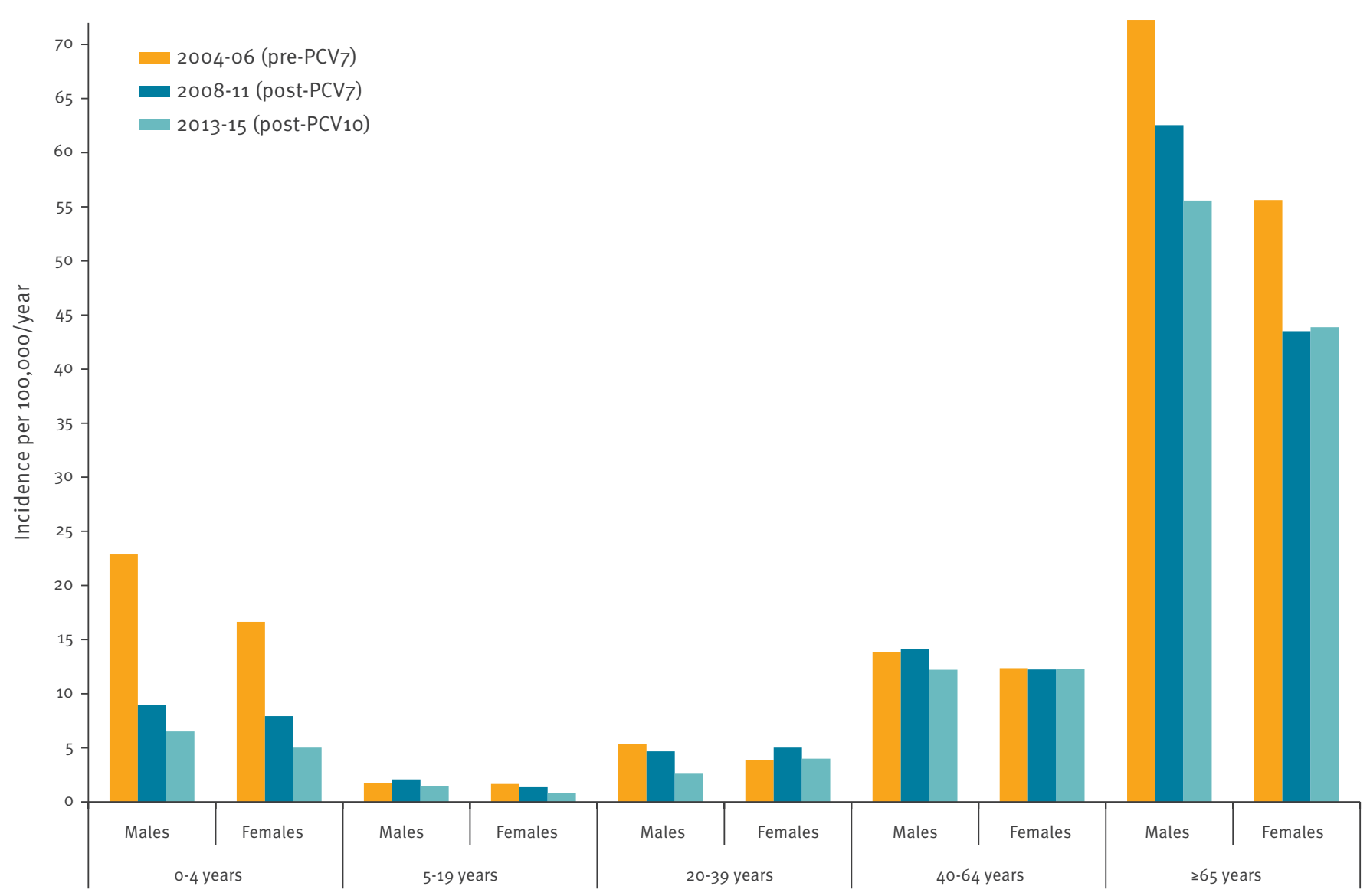

PCV: pneumococcal conjugate vaccine.

Study period: pre-PCV7 (June 2004-May 2006) post-PCV7 (June 2008-May 2011) and post-PCV10 (June 2013-May 2015).

reported an increase in the incidence of pneumococcal pneumonia in mothers of young infants after introduction of $\mathrm{PCV}_{7}$ in the United Kingdom (UK) [22]. In the Netherlands, a significant increase in IPD incidence was observed in middle-aged women 2-4 years after introduction of $\mathrm{PCV}_{7}$, mainly due to the emergence of serotype 1 , which was not observed in men in the same age group [23]. Whether this was due to non-PCV7 serotype replacement or to a secular trend needs to be established because serotype 1 is a naturally fluctuating serotype [24]. In May 2011, the 10-valent pneumococcal conjugate vaccine (PCV10) including serotype 1 was introduced for Dutch infants.

The objective of this study was to explore differences in IPD incidence between men and women before and after $\mathrm{PCV}_{7}$ and $\mathrm{PCV}_{10}$ introduction by using national surveillance data up to May 2015.

\section{Methods}

\section{Study population and data collection}

The Dutch pneumococcal surveillance is based on data from nine sentinel laboratories covering different regions of the Netherlands and ca $25 \%$ of the Dutch population (ca 4.2 million inhabitants, including 2.07 million men and 2.11 million women). The participant laboratories, selected for geographic location and reliability for submitting isolates, have not changed over time during the study period $[14,16]$. In addition, we have no indication that surveillance sensitivity has changed over the years. Pneumococcal isolates of all IPD patients, defined as patients with $S$. pneumoniae isolated from blood or cerebrospinal fluid (CSF), were submitted to the Netherlands Reference Laboratory for Bacterial Meningitis (NRLBM) for serotyping by coagglutination and capsular swelling (Quellung reaction) using specific antisera (Statens Serum Institute, Denmark). Pneumococcal serotypes and demographic data including age and sex were available for IPD cases from June 2004 up to May 2015. 


\section{FIGURE 2}

Age-specific female/male incidence ratio of invasive pneumococcal disease in the pre- and post-PCV periods, the Netherlands, 2004-15 ( $\mathrm{n}=4,303)$

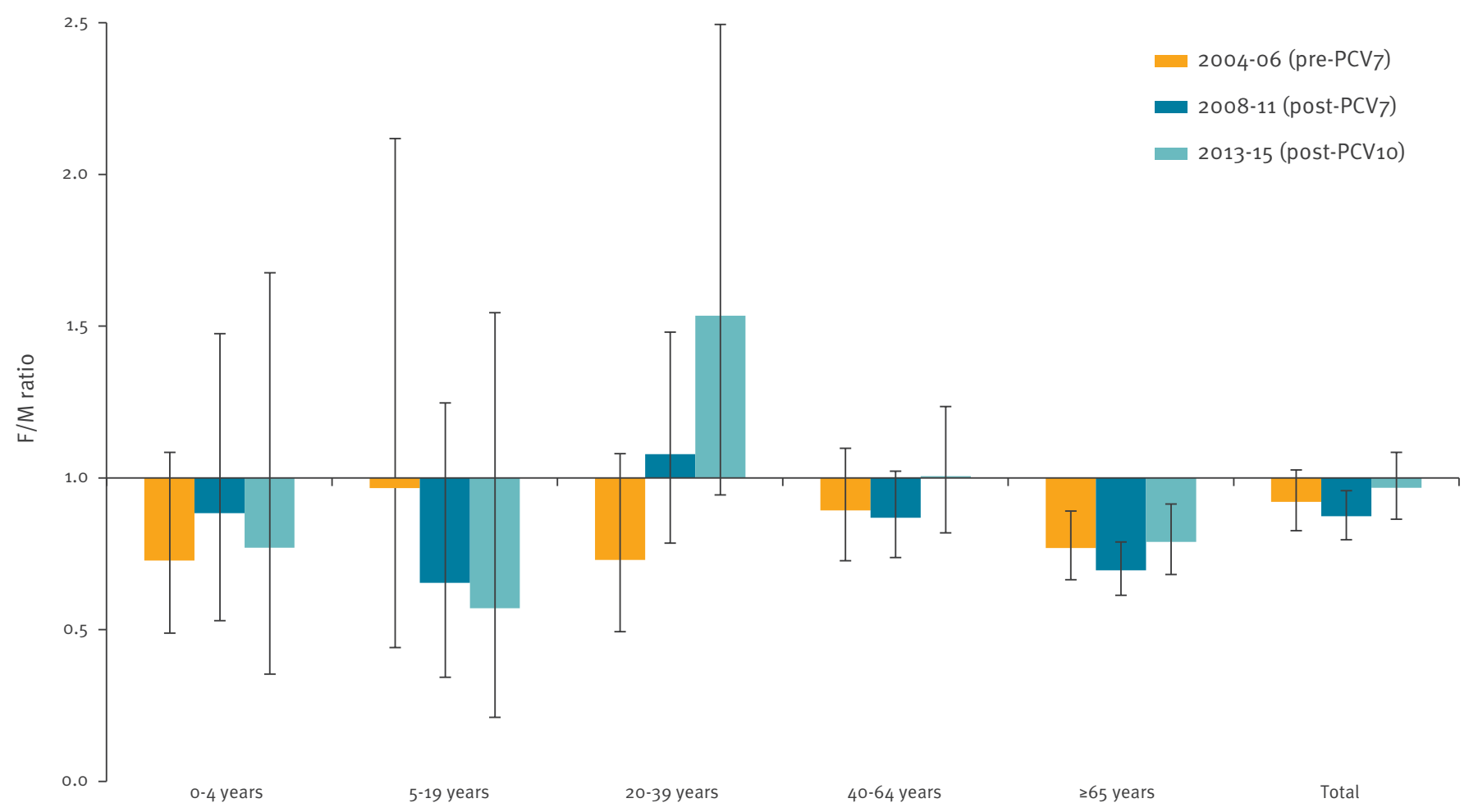

F/M: female/male; PCV: pneumococcal conjugate vaccine.

Study period: pre-PCV7: June 2004-May 2006; post-PCV7: June 2008-May 2011; post-PCV10: June 2013-May 2015.

Black bars indicate $95 \%$ confidence intervals.

In addition, clinical information including clinical syndromes (categorised as (i) meningitis, (ii) invasive pneumonia (without meningitis), (iii) bacteraemia without focus and (iv) bacteraemia with other focus (without meningitis or invasive pneumonia)), clinical outcome (death in hospital and/or death within 30 days after first reported blood/CSF culture positive for $S$. pneumoniae), admission to an intensive care unit (ICU), and presence of underlying conditions (immunocompromising conditions and other comorbidities) were retrospectively extracted for IPD patients from June 2004 up to May 2012 from hospital medical records as described $[15,16,25]$. Clinical data from the post-PCV10 period (1 June 2013 to 31 May 2015) were not available.

\section{Data analysis}

We assessed sex-specific IPD incidences during a pre$\mathrm{PCV}_{7}$ (1 June 2004 to 31 May 2006), post-PCV7 (1 June 2008 to 31 May 2011) and post-PCV1o period (1 June 2013 to 31 May 2015) and calculated the female/male (F/M) incidence ratio. The first two years after introduction of PCV 7 and PCV10 (1 June 2006 to 31 May 2008 and 1 June 2011 to 31 May 2013) were regarded as transition period and not included.
Changes in IPD incidences, comparing post-PCV7 to pre-PCV 7 and post-PCV10 to post-PCV 7 were assessed for men and women separately by calculating relative risks (RR). To investigate sex differences in direct and indirect effects (i.e. changes in IPD incidences) after $\mathrm{PCV}_{7}$ or $\mathrm{PCV}_{10}$ introduction, the interaction between sex and change in IPD incidence (RR post-PCV7 to pre$\mathrm{PCV}_{7}$ or RR post-PCV10 to post-PCV7, respectively) was assessed by calculating the F/M risk ratio of RRs (dividing the RR in women by the RR in men).

Likewise, sex-specific differences in the proportion of clinical syndromes, in clinical outcome and in underlying conditions were assessed in the pre- $\mathrm{PCV}_{7}$ and post$\mathrm{PCV}_{7}$ period ( $\mathrm{F} / \mathrm{M}$ ratio of proportions). Also changes in the proportion of clinical syndromes, in clinical outcome and in underlying conditions after $\mathrm{PCV}_{7}$ were assessed for men and women separately (RR post$\mathrm{PCV}_{7}$ to pre-P(V 7 ). The interaction between sex and change in proportions was assessed by calculating the $\mathrm{F} / \mathrm{M}$ risk ratio of RRs. Cases without clinical data were excluded from these analyses.

We further explored if there was a sex-specific preference in certain serotypes causing IPD, defined as an 


\section{FIGURE 3}

Incidences of invasive pneumococcal disease per serotype group in 20-39 year-old men and women pre-PCV7, post-PCV7 and post-PCV10, the Netherlands, 2004-15 ( $\mathrm{n}=324)$

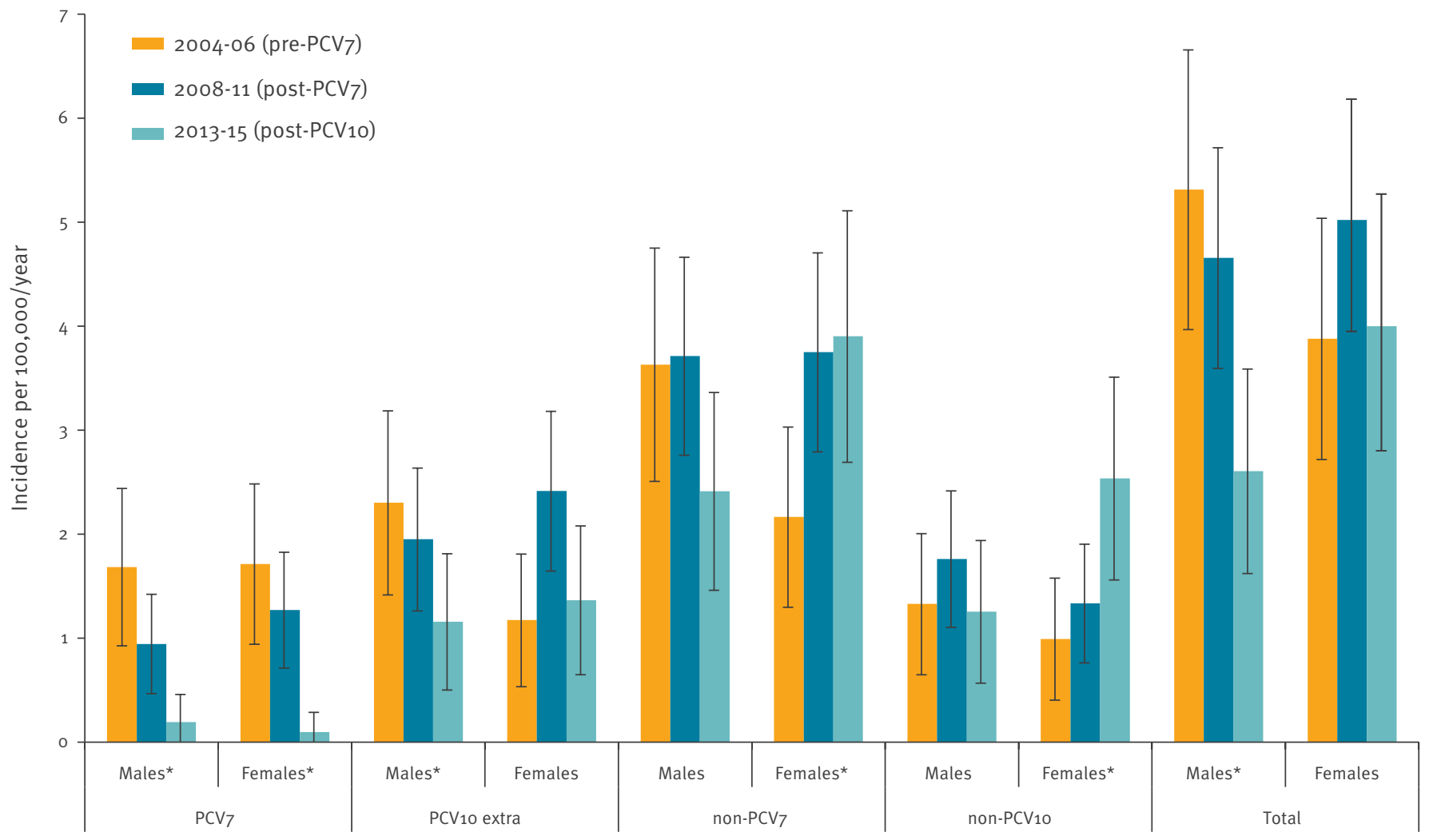

IPD: invasive pneumococcal disease; PCV: pneumococcal conjugate vaccine.

Study period: pre-PCV7: June 2004-May 2006; post-PCV7: June 2008-May 2011; post-PCV10: June 2013-May 2015, Black bars indicate 95\% confidence intervals.

* Indicates a significant difference (p value $0_{0.05}$ ) in IPD incidence comparing post-PCV10 to pre-PCV7.

intrinsic and stable factor influencing the occurrence of a serotype that would potentially explain differences in overall IPD susceptibility between sexes. Potential sex-specific preferences in serotypes causing IPD were assessed by calculating the serotype-specific $\mathrm{F} / \mathrm{M}$ ratio. We used all data from 2004 to 2015 (including the transition years) from patients aged 5 years and older $(n=6,628)$ to account for changes over time, without any exclusion. Younger children $(n=276)$ were not taken into account for this analysis because the numbers of IPD per serotype were too small to analyse them as a separate group. The serotype-specific $\mathrm{F} / \mathrm{M}$ ratios were compared with the average $\mathrm{F} / \mathrm{M}$ ratio (dividing the total number of cases in women by the total number of cases in men across all serotypes in patients aged 5 years and older) using Fisher's exact test (SPSS version 22). A p value of $<0.05$ was considered statistically significant.

Analyses were stratified by age group (0-4, 5-19, 20-39, 40-64 and $\geq 65$ years-old). Serotypes were divided in $\mathrm{PCV}_{7}$ serotypes (i.e. serotype 4, 6B, 9V, 14,
$18 \mathrm{C}, 19 \mathrm{~F}$ and $23 \mathrm{~F}$ ), additional PCV10 serotypes ('PCV10 extra': i.e. serotype 1, 5 and $7 \mathrm{~F}$ ) and non-PCV7 or non$P C V_{10}$ serotypes (all serotypes not included in $\mathrm{PCV}_{7}$ or PCV10, respectively). Also, as a sensitivity analysis, serotype $6 \mathrm{~A}$ was included as a $\mathrm{PCV}_{7}$ serotype and results remained similar (data not shown).

Incidences were calculated as the number of cases per 100,000 persons per year. National incidences were calculated by dividing the population number for each year (StatLine Statistics, the Netherlands) by 4 reflecting the coverage of the sentinel surveillance laboratories ( $25 \%$ of the Dutch population). Differences in incidences and proportions were tested with chisquared or Fisher's exact test, as appropriate, and for $\mathrm{F} / \mathrm{M}$ incidence ratio, $\mathrm{F} / \mathrm{M}$ ratio of proportions, serotypespecific $\mathrm{F} / \mathrm{M}$ ratio, relative risks and $\mathrm{F} / \mathrm{M}$ risk ratio of RRs, 95\% confidence intervals $(\mathrm{Cl})$ were calculated using $2 \times 2$ tables (z-distribution) [26]. 


\section{FIGURE 4}

Serotype-specific female/male ratio for causing invasive pneumococcal disease in patients 5 years and older, the Netherlands, 2004-15 ( $\mathrm{n}=6,628)$

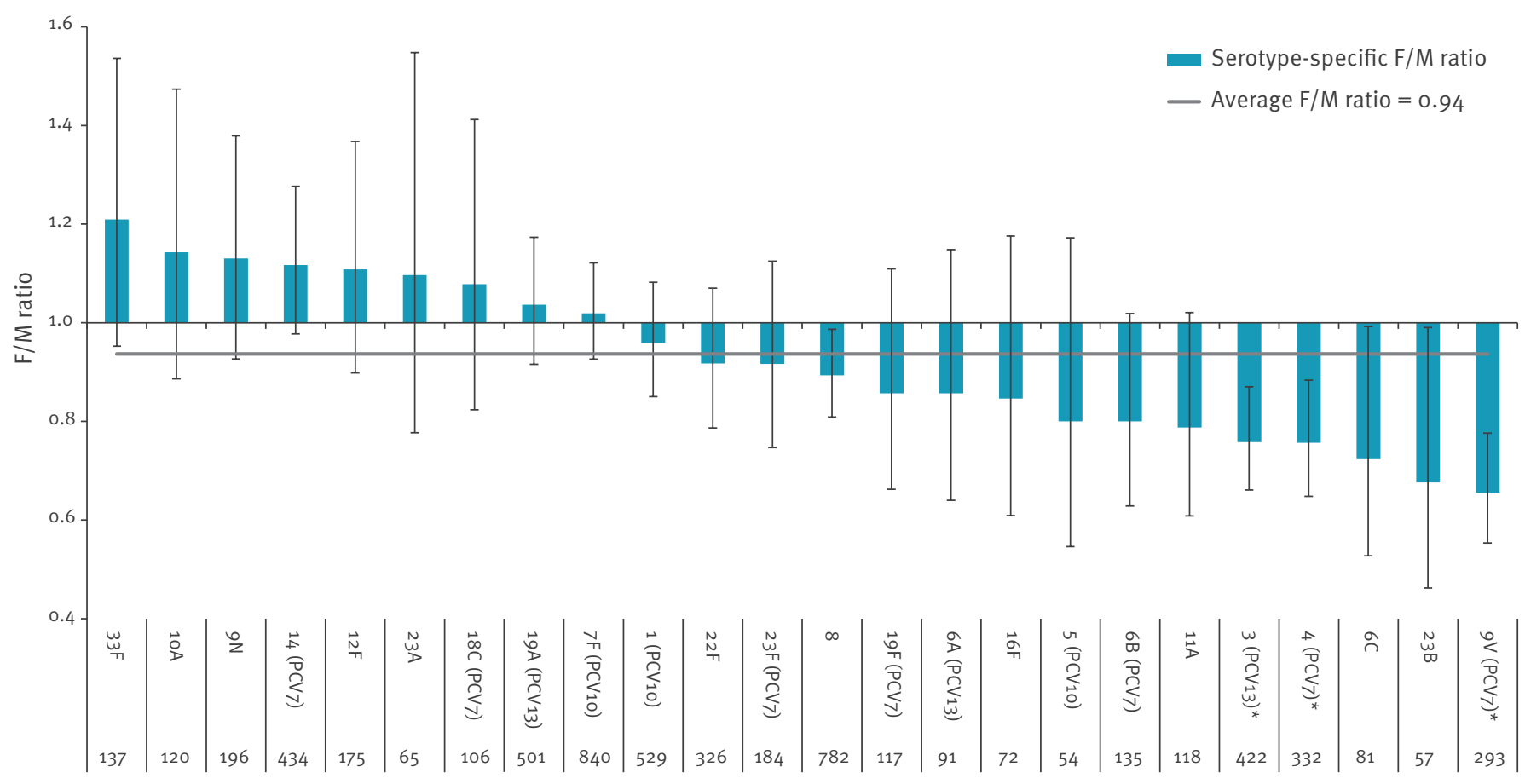

F/M: female/male; IPD: invasive pneumococcal disease; PCV: pneumococcal vaccine.

All (additional) serotypes included in the 7, 10 and (not introduced) 13-valent PCV ('PCV13 extra': i.e. serotype 3, 6A and 19A) are shown. Of the non-vaccine serotypes, all serotypes with more than 50 cases during the entire study period are shown. The horizontal line represents the average $\mathrm{F} / \mathrm{M}$ ratio across all serotypes (0.94). The numbers on the $\mathrm{x}$ axis represent the total number of isolates per serotype. Black bars indicate $95 \%$ confidence intervals.

* Indicates a significant difference ( $\mathrm{p}$ value $<0.05$ ) between the serotype-specific F/M ratio compared and the F/M ratio all other serotypes combined.

\section{Results}

Overall, 6,906 patients were affected by IPD in the period from 1 June 2004 to 31 May 2015; 3,592 males and 3,314 females, including 169 males and 107 females younger than 5 years. For the pre- and postPCV periods (without the transition years included), overall 4,303 patients had IPD; 2,227 males and 2,076 females, including 106 males and 79 females younger than 5 years.

\section{Incidence of invasive pneumococcal disease pre- and post-PCV7/10}

Figure 1 shows the age and sex-specific IPD incidence in the pre-PCV7, post-PCV 7 and post- $P \mathrm{PV}_{10}$ period. The IPD incidence in men was higher than in women for all age groups, except for the 20-39 year-olds in both post-PCV periods and the 40-64 year-olds in the post$\mathrm{PCV} 10$ period. The largest difference in IPD incidence between men and women (in absolute numbers, Figure 1) was observed in those at highest risk, i.e. children younger than 5 years and persons 65 years and older, but the $F / M$ ratio was only significant for those 65 years and older (Figure 2, F/M incidence ratio).

The Table presents IPD incidences (and absolute number of cases) for male and female IPD patients in the pre-PCV7, post- $P \mathrm{PV}_{7}$ and post-PCV 10 periods and the change in IPD incidence for men and women separately (RR comparing post-PCV7 to pre-PCV7 and $R R$ post-PCV10 to post-P(V7). In addition, we used the $\mathrm{F} / \mathrm{M}$ risk ratio of RRs (post-PCV7 vs pre- $\mathrm{PCV}_{7}$ and post$P C V_{10}$ vs post-P(V10) to investigate sex differences in direct and indirect effects. Comparing post-PCV 7 to pre- $\mathrm{PCV}_{7}$, there was a significant decrease in overall IPD incidence for children younger than 5 years and and people 65 years and older in both sexes (Table: in those younger than 5 years, the male RR was $0.39(95 \% \mathrm{Cl}$ : $0.25-0.60)$ and the female RR was 0.48 (95\% Cl: $0.29-$ 0.77 ), and in those 65 years and older, the male RR was $0.87(95 \% \mathrm{Cl}: 0.76-0.99)$ and the female RR was 0.78 (95\% Cl: $0.68-0.90)$. The overall reduction ( $F / M$ risk ratio of RRs post- $\mathrm{PCV}_{7}$ vs pre- $\mathrm{PCV}_{7}$ ) in IPD was 

not significantly different between men and women of these age groups (Table).

Also in other age groups, there was no significant interaction between change in IPD incidence and sex comparing post-PCV7 to pre-PCV7. However, in the 20-39 year-olds, the $\mathrm{F} / \mathrm{M}$ risk ratio of RRs for $\mathrm{PCV} 10$ serotype IPD was 2.43 (95\% Cl: 1.07-5.50), owing to a significant increase in PCV10 serotype IPD in women ( $R R=2.06$; $95 \% \mathrm{Cl}: 1.10-3.87)$ and a non-significant reduction in men ( $R R=0.85 ; 95 \% \mathrm{Cl}: 0.50-1.43)$, which indicated a statistically significant difference in replacement disease by PCV10 serotypes (mainly 1 and $7 F$, data not shown). As a result, women showed a non-significant increase in IPD incidence comparing the pre-PCV 7 to post-PCV7 (from 3.9/100,000 to 5.0/100,000) period, whereas the incidence decreased in men of the same age (from 5.3/100,000 to 4.7/100,000, Figure 3). In 40-64 year-olds of both sexes, IPD incidence remained stable after $\mathrm{PCV}_{7}$ introduction.

After PCV10 introduction, IPD caused by the additional PCV10 serotypes decreased in all age groups and in both sexes, suggesting $\mathrm{PCV}_{10}$ herd protection, although this was only significant for men aged 40-64 ( $R R=0.67 ; 95 \% \mathrm{Cl}: 0.45-0.99)$ and women 65 years and older $(R R=0.60 ; 95 \% \mathrm{Cl}: 0.42-0.87$, Table). In addition, $\mathrm{PCV}_{7}$ serotype IPD continued to decrease. These on-going effects of herd protection against $\mathrm{PCV}_{7}$ and recently introduced $\mathrm{PCV}_{10}$ resulted in a non-significant decline in overall IPD incidence for all except women aged 40 and older. In women 40 years and older, $P C V_{7} / 10$ herd protection was offset by a significant increase in non-PCV10 serotype IPD, which was not observed in men, a group where IPD incidence declined. As a result, IPD incidence in the 40-64 year-olds became similar in women and men (12.3/100,000 vs 12.2/100,000). However, we did not observe a significantly different change in overall IPD incidence between men and women in this age group (F/M risk ratio of RRs post-PCV10 vs post-PCV7, Table). Also in other age groups, there was no significant interaction between change in overall IPD incidence and sex comparing post-PCV10 to post-PCV7. After PCV10 introduction, non-PCV10 serotype IPD incidence in 20-39 year-old women increased $(R R=1.90 ; 95 \% \mathrm{Cl}$ : 1.07-3.38), whereas it decreased in men ( $R R=0.71$; $95 \% \mathrm{Cl}$ : $0.37-1.37, \mathrm{~F} / \mathrm{M}$ risk ratio of $\mathrm{RRs}=2.67 ; 95 \% \mathrm{Cl}$ : 1.11-6.39).

\section{Clinical syndromes, outcomes and underlying} conditions pre- and post-PCV7

Comparing post-PCV 7 to pre-PCV7, no major differences were observed between sexes regarding shifts in the proportion of different clinical syndromes, outcomes and underlying conditions. However, some significant differences within the pre- and/or post-PCV7 periods, and small but significantly different shifts in proportions were observed between male and female IPD patients.
Clinical syndromes

In the pre- $\mathrm{PCV}_{7}$ period, the overall proportion (without stratification for age) of IPD patients with invasive pneumonia was significantly higher in male than female patients (76 vs $71 \%$; F/M ratio of proportions: $\mathrm{RR}=0.93 ; 95 \% \mathrm{Cl}: 0.87-0.98)$. After stratification for age, this remained significant for the 20-39 year-olds and those 65 years and older. In the post- $\mathrm{PCV}_{7}$ period (June 2008-May 2011), the distribution of clinical syndromes in all IPD patients was not significantly different between male and female patients. However, in male IPD patients aged 5-19 years, the proportion of pneumonia was significantly higher than in female patients (80 vs 40\%: F/M ratio of proportions: $R R=0.50 ; 95 \%$ $\mathrm{Cl}: 0.26-0.96)$, whereas for 20-39 year-old men, meningitis was significantly more common (20 vs $8 \%$; F/M ratio of proportions: $\mathrm{RR}=0.39 ; 95 \% \mathrm{Cl}: 0.16-0.96)$. The changes in distribution of clinical syndromes after $\mathrm{PCV}_{7}$ introduction (F/M risk ratio of $\mathrm{RRs}$ ) were not significantly different between male and female patients except in 20-39 year-olds, in whom the increased proportion of pneumonia in female patients (from 68 to $77 \%)$ differed significantly from the decreased proportion (from 88 to $73 \%$ ) in male patients ( $F / M$ risk ratio of RRs $=1.37 ; 95 \% \mathrm{Cl}: 1.01-1.86)$.

\section{Outcomes}

In the pre- and post- $\mathrm{PCV}_{7}$ period, the overall case fatality and the proportion of ICU admissions (without stratification for age) were not significantly different between male and female IPD patients. The decline in case fatality after $\mathrm{PCV}_{7}$ introduction did not differ significantly between male (from 15 to $12 \%$ ) and female patients (from 18 to $11 \%$; F/M risk ratio of $\mathrm{RRs}=0.79$; $95 \% \mathrm{Cl}: 0.54-1.13)$. Nor were changes in case fatality and proportion of ICU admissions significantly different between male and female patients after stratification for age.

\section{Underlying conditions}

In the pre- and post- $\mathrm{PCV}_{7}$ period, the overall proportion (without stratification for age) of male IPD patients with an immunocompromising condition was significantly higher compared with that of female patients, with 21 vs $16 \%$ pre-PCV7 (F/M ratio of proportions $=0.78 ; 95 \%$ $\mathrm{Cl}: 0.61-0.99)$ and 21 vs $13 \%$ post- $\mathrm{PCV}_{7}$ (F/M ratio of proportions $=0.64 ; 95 \% \mathrm{Cl}: 0.51-0.79)$, respectively. After stratification for age, this remained significant for patients 65 years and older. Also the change in the overall proportion of patients with an immunocompromising condition after $\mathrm{PCV}_{7}$ introduction was significantly different between male and female patients ( $F / M$ risk ratio of $\mathrm{RRS}=0.82 ; 95 \% \mathrm{Cl}: 0.67-0.99)$, indicating a significantly higher decrease in women compared with the stable proportion in men. However, after stratification for age, there were no significant differences in changes in immunocompromising conditions between male and female patients following $\mathrm{PCV}_{7}$ introduction. The overall proportion of patients with any comorbidity was higher in male IPD patients than in female patients, with 76 vs $74 \%$ pre-PCV7 (F/M ratio of 


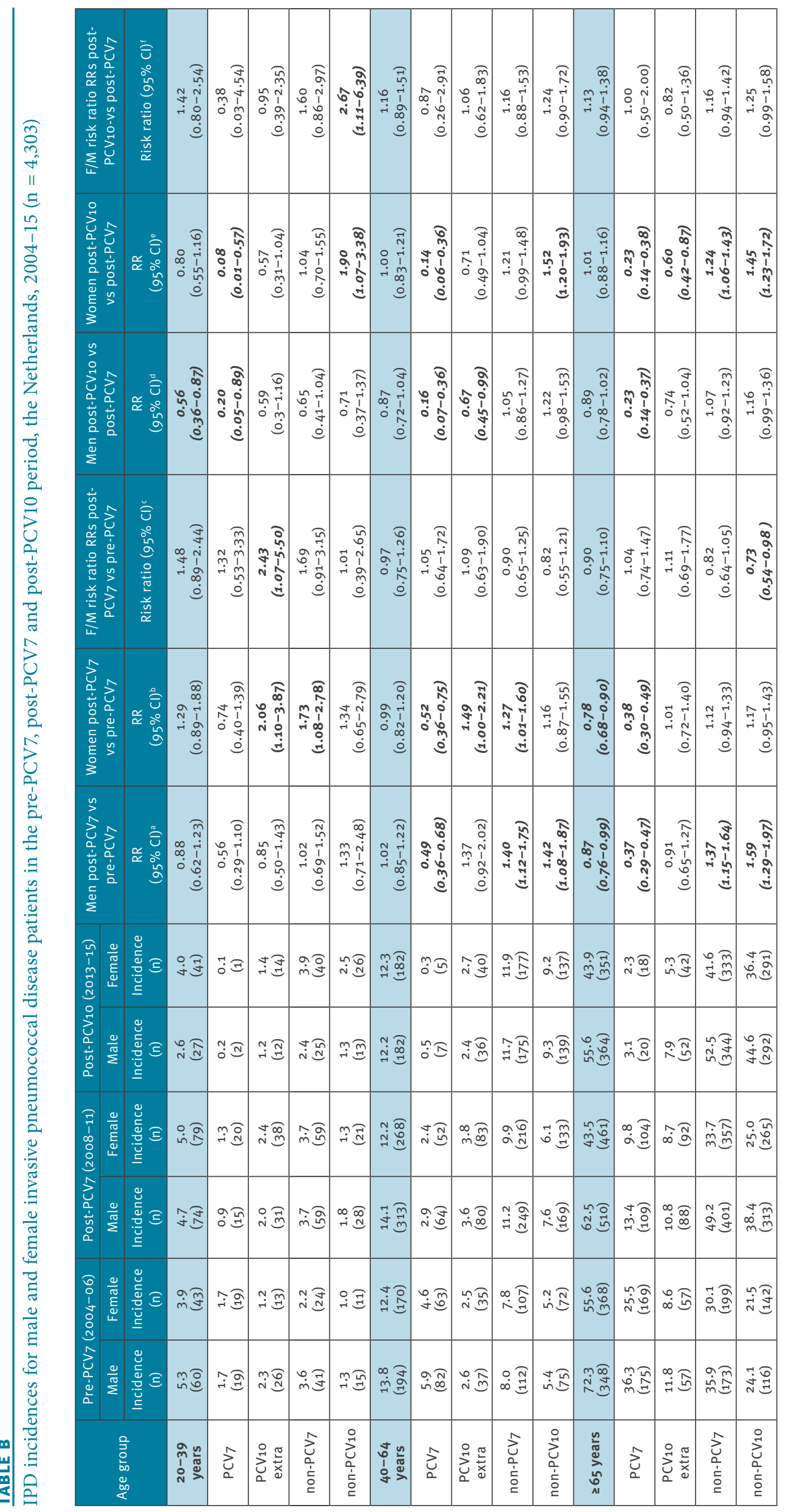


proportions $=0.98 ; 95 \% \mathrm{Cl}: 0.92-1.05)$ and $77 \mathrm{vs} 72 \%$ post-PCV7 (F/M ratio of proportions $=0.94 ; 95 \% \mathrm{Cl}$ : 0.89-0.99). After stratification for age, this was significant for patients 65 years and older pre-PCV 7 and for 40-64 year-old patients post-PCV7. The overall change in the proportion of patients with any comorbidity following $\mathrm{PCV}_{7}$ introduction was not significantly different between male and female patients ( $F / M$ risk ratio of RRs $=0.96 ; 95 \% \mathrm{Cl}: 0.88-1.04)$ with or without stratification for age.

Serotype-specific female/male ratio for invasive pneumococcal disease

Figure 4 shows the serotype-specific F/M ratio. Overall, 6,628 patients aged 5 years and older $(3,422$ males, 3,206 females) were affected by IPD in the period from 1 June 2004 to 31 May 2015. The average F/M ratio across all serotypes was 0.94 . Only serotypes 3,4 and $9 \mathrm{~V}$ were significantly associated with male sex $(\mathrm{F} / \mathrm{M}$ ratio $=0.76 ; p=0.026, F / M$ ratio $=0.76 ; p=0.047$ and $\mathrm{F} / \mathrm{M}$ ratio $=0.66 ; p=0.002$, respectively).

\section{Discussion}

Our findings confirm the importance of sex as an epidemiological factor in IPD. We observed structurally higher IPD incidences in men in all age groups, with the exception of 20-39 year-olds after implementation of $\mathrm{PCV}_{7}$ and of 40-64 year-olds after implementation of PCV10. These observations illustrate a sex-specific differential impact of post-PCV dynamics.

The structural excess in IPD incidence in boys younger than 5 years has been attributed to anatomical or early hormonal differences predisposing to differences in immunity [27-29]. Likewise, the higher susceptibility for IPD in elderly men could be explained by sex-based inactivation of the $X$ chromosome, resulting in differences in immunity $[1,4,5]$. Also a higher prevalence of underlying conditions in the male population such as chronic cardiovascular and renal disease, malignancies [30] or tobacco use is likely to play a role [31]. This is reflected in a significantly higher proportion of immunocompromising conditions in male IPD patients pre- and post-PCV7. We only found a serotype-specific preference to affect men and women differently in three of 24 serotypes; therefore an individual serotype-specific (or serotype-related) factor for explaining the difference in IPD susceptibility is unlikely.

In 20-39 year-olds, IPD incidence in women increased post-PCV7 and became higher than in men, in whom IPD incidence had decreased. This reflected a significant increase in IPD caused by the additional PCV10 serotypes (mainly serotypes 1 and $7 \mathrm{~F}$ ). Likewise, previous analysis of Dutch surveillance data 2-4 years after $\mathrm{PCV}_{7}$ introduction showed an increase in IPD incidence in women (20-44 years-old) caused by an increase in serotype 1 [23]. After PCV7 was replaced by PCV10, covering serotypes 1 and $7 F$, herd effects may have reduced the elevated burden of IPD in 20-39 year-old women. Indeed, herd protection of PCV10 was established, and overall IPD incidence as well as IPD caused by PCV 10 serotypes decreased in both sexes. However, a significant increase in non-PCV10 type IPD was, again, exclusively observed in women and IPD incidence remained higher in women than in men post-PCV10. The increase in non-PCV 10 type IPD (attributable to several serotypes) suggests a vaccine induced effect rather than natural fluctuation of a single serotype.

Also, in a recent study from the United States, IPD incidence was generally higher in male people, but after PCV13 introduction, IPD incidence among 18-39 yearold black women became slightly higher than in men [20]. Socially defined roles may explain this phenomenon. Women of childbearing age could be at increased risk for replacement disease because of close contact with $\mathrm{PCV} 7 / 10$-vaccinated children as was hypothesised in other studies $[22,23]$. In Scotland before $\mathrm{PCV}_{7}$ introduction, a higher IPD incidence was observed in 35-49 year-old women based on data from 1992 to 2007 [32]. Increased carriage of non-vaccine pneumococcal serotypes in parents of vaccinated children compared with parents of unvaccinated children has been well established $[12,33]$. Although these studies did not analyse men and women separately, the importance of sex is further supported by a study on pertussis, which showed a higher transmission rate between infants and mothers compared with fathers [34].

In other non-vaccinated age groups, PCV 10 herd effects became apparent as well, but again with a sexspecific differential impact. In men 40 years and older, IPD incidence declined further during the post-PCV 10 period, whereas herd effects in women of the same age groups were offset by a significant increase in IPD caused by non-PCV10 serotypes. This could suggest that for women 40 years and older, after an initial overall reduction in IPD due to $\mathrm{PCV}_{7}$ herd effects, a new plateau phase in IPD incidence has been reached using current vaccination strategies.

After introduction of $\mathrm{PCV}_{7}$, shifts in circulating serotypes were associated with significant changes in clinical outcome, such as a lower overall case fatality [25]. Our findings confirm that this is the case for both sexes at the time point 5 years after $\mathrm{PCV}_{7}$ introduction. Pre- and post-PCV7, the case fatality and ICU admission rates between male and female patients were not significantly different.

A limitation of our study is that it was an ecological study, so one should be cautious about interpreting findings as causally related to introduction of vaccination. In addition, not accounting for multiple testing in statistical analysis and some results being borderline significant, our results should be regarded as explorative analysis and need to be interpreted with caution. Furthermore, we had no information whether or not IPD patients were parents and/or had close contact with children and therefore could not further assess the proposed mechanism which could have resulted in 
the observed differences in 20-39 year-old patients. Nevertheless, our study provides important insights into structural sex differences in IPD incidence and different indirect effects after $P C V_{7} / 10$ introduction. This finding indicates that an intervention in a complex ecosystem can result in (temporary) changes in IPD dynamics but needs to be confirmed by others.

\section{Conclusion}

This study confirms the importance of sex in IPD incidence. We have shown that shifts in serotypes can cause increased IPD incidence rates. Although IPD surveillance studies have been performed in many countries, data on sex differences are scarce. We invite other investigators to stratify their pre- and postpneumococcal vaccination IPD data by sex. Continued surveillance of IPD incidence and outcome by sex is important to evaluate the direct and indirect long-term effects of pneumococcal conjugate vaccination in the population.

\section{Conflict of interest}

Gertjan Wagenvoort received a lecturing fee from Pfizer.

Clinical data collection was supported by an unrestricted research grant from GlaxoSmithKline Pharmaceuticals and Pfizer Pharmaceuticals. The sponsors played no role in the study design, data analyses and preparation, review, or approval of the manuscript.

\section{Authors' contributions}

Data administration, data analysis, interpretation of data, drafting of the manuscript: Gertjan Wagenvoort and Mirjam Knol. Interpretation of data, drafting of the manuscript: Elisabeth Sanders, Hester E. de Melker, Bart Vlaminckx. Drafting manuscript, interpretation of data and serotyping: Arie van der Ende.

\section{References}

1. Fish EN. The X-files in immunity: sex-based differences predispose immune responses. Nat Rev Immunol. 2008;8(9):737-44. DOI: 10.1038/nri2394 PMID: 18728636

2. Roberts CW, Walker W, Alexander J. Sex-associated hormones and immunity to protozoan parasites.Clin Microbiol Rev. 2001;14(3):476-88. DOI: 10.1128/CMR.14-3.476-488.2001 PMID: 11432809

3. Kadioglu A, Cuppone AM, Trappetti C, List T, Spreafico A, Pozzi G, et al. Sex-based differences in susceptibility to respiratory and systemic pneumococcal disease in mice. Infect Dis. 2011;204(12):1971-9. DOI: 10.1093/infdis/jir657 PMID: 22021621

4. van Lunzen J, Altfeld M. Sex differences in infectious diseasescommon but neglected.J Infect Dis. 2014;209(Suppl 3):S79-80. DOI: 10.1093/infdis/jiu159 PMID: 24966193

5. Falagas ME, Mourtzoukou EG, Vardakas KZ. Sex differences in the incidence and severity of respiratory tract infections. Respir Med. 2007;101(9):1845-63. DOI: 10.1016/j.rmed.2007.04.011 PMID: 17544265

6. Gutiérrez F, Masiá M, Mirete C, Soldán B, Rodríguez JC, Padilla $S$, et al. The influence of age and gender on the populationbased incidence of community-acquired pneumonia caused by different microbial pathogens. J Infect. 2006;53(3):166-74. DOI: 10.1016/j.jinf.2005.11.006 PMID: 16375972

7. Jensen-Fangel S, Mohey R, Johnsen SP, Andersen PL, Sørensen HT, Ostergaard L. Gender differences in hospitalization rates for respiratory tract infections in Danish youth.Scand J Infect
Dis. 2004;36(1):31-6. DOI: 10.1080/00365540310017618 PMID: 15000556

8. Millett ER, Quint JK, Smeeth L, Daniel RM, Thomas SL. Incidence of community-acquired lower respiratory tract infections and pneumonia among older adults in the United Kingdom: a population-based study.PLoS One. 2013;8(9):e75131. DOI: 10.1371/journal.pone.0075131 PMID: 24040394

9. Usuf E, Bottomley C, Adegbola RA, Hall A. Pneumococcal carriage in sub-Saharan Africa--a systematic review.PLoS One. 2014;9(1):e85001. DOI: 10.1371/journal.pone.0085001 PMID: 24465464

10. Watson K, Carville K, Bowman J, Jacoby P, Riley TV, Leach AJ, et al. Upper respiratory tract bacterial carriage in Aboriginal and non-Aboriginal children in a semi-arid area of Western Australia. Pediatr Infect Dis J. 2006;25(9):782-90. DOI: 10.1097/01.inf.0000232705.49634.68 PMID: 16940834

11. Syrjänen RK, Kilpi TM, Kaijalainen TH, Herva EE, Takala AK. Nasopharyngeal carriage of Streptococcus pneumoniae in Finnish children younger than 2 years old.J Infect Dis. 2001;184(4):451-9. DOI: 10.1086/322048 PMID: 11471103

12. van Gils EJ, Veenhoven RH, Hak E, Rodenburg GD, Bogaert D, ljzerman EP, et al. Effect of reduced-dose schedules with 7-valent pneumococcal conjugate vaccine on nasopharyngeal pneumococcal carriage in children: a randomized controlled trial. JAMA. 2009;302(2):159-67. DOI: 10.1001/jama.2009.975 PMID: 19584345

13. Spijkerman J, van Gils EJ, Veenhoven RH, Hak E, Yzerman $E P$, van der Ende A, et al. Carriage of Streptococcus pneumoniae 3 years after start of vaccination program, the Netherlands. Emerg Infect Dis. 2011;17(4):584-91. DOI: 10.3201/ eid1704.101115 PMID: 21470445

14. Jansen AG, Rodenburg GD, van der Ende A, van Alphen L, Veenhoven RH, Spanjaard L, et al. Invasive pneumococcal disease among adults: associations among serotypes, disease characteristics, and outcome. Clin Infect Dis. 2009;49(2):e239. DOI: 10.1086/600045 PMID: 19522653

15. Rodenburg GD, de Greeff SC, Jansen AG, de Melker HE, Schouls LM, Hak E, et al. Effects of pneumococcal conjugate vaccine 2 years after its introduction, the Netherlands. Emerg Infect Dis. 2010;16(5):816-23. DOI: 10.3201/eid1605.091223 PMID: 20409372

16. van Deursen AM, van Mens SP, Sanders EA, Vlaminckx BJ, de Melker HE, Schouls LM, et al. Invasive pneumococcal disease and 7-valent pneumococcal conjugate vaccine, the Netherlands. Emerg Infect Dis. 2012;18(11):1729-37. DOI: 10.3201/eid1811.120329 PMID: 23092683

17. Myint TT, Madhava H, Balmer P, Christopoulou D, Attal S, Menegas D, et al. The impact of 7-valent pneumococcal conjugate vaccine on invasive pneumococcal disease: a literature review. Adv Ther. 2013;30(2):127-51. DOI: 10.1007/ S12325-013-0007-6 PMID: 23397399

18. Ladhani SN, Slack MP, Andrews NJ, Waight PA, Borrow R, Miller $\mathrm{E}$. Invasive pneumococcal disease after routine pneumococcal conjugate vaccination in children, England and Wales.Emerg Infect Dis. 2013;19(1):61-8. DOI: 10.3201/eid1901.120741 PMID: 23259937

19. Griffin MR, Zhu Y, Moore MR, Whitney CG, Grijalva CGUS. U.S. hospitalizations for pneumonia after a decade of pneumococcal vaccination. N Engl J Med. 2013;369(2):155-63. DOI: 10.1056/NEJMoa1209165 PMID: 23841730

20. de St Maurice A, Schaffner W, Griffin MR, Halasa N, Grijalva CG. Persistent Sex Disparities in Invasive Pneumococcal Diseases in the Conjugate Vaccine Era.J Infect Dis. 2016;214(5):792-7. DOI: 10.1093/infdis/jiw222 PMID: 27247342

21. van Lier EA, Oomen PJ, Mulder M, Conyn-van Spaendonck MAE, Drijfhout IH, de Hoogh PAAM, de Melker HE. Vaccinatiegraad Rijksvaccinatieprogramma Nederland Verslagjaar 2013. [Immunisation coverage national immunisation programme in the Netherlands: year of report 2013]. Bilthoven: Rijksinstituut voor Volksgezondheid en Milieu. 2013. RIVM Rapport 150202001. Dutch. Available from: http://www.rivm.nl/en/ Documents_and_publications/Scientific/Reports/2013/juni/ Immunisation_coverage_National_Immunisation_Programme in_the_Netherlands_Year_of_report_2013

22. Hak E, Shea KM, Jick SS. Association of infant pneumococcal vaccination with pneumococcal pneumonia among mothers: a nested case-control study using the GPRD.Vaccine. 2013;31(12):1590-6. DOI: 10.1016/j.vaccine.2013.01.018 PMID: 23357195

23. Van Mens SP, Van Deursen AM, Meijvis SC, Vlaminckx BJ, Sanders EA, De Melker HE, et al. Increased incidence of serotype-1 invasive pneumococcal disease in young female adults in The Netherlands. Epidemiol Infect. 2014;142(9):19969. DOI: $10.1017 /$ So950268813002860 PMID: 24229845 
24. Harboe ZB, Benfield TL, Valentiner-Branth P, Hjuler T, Lambertsen L, Kaltoft M, et al. Temporal trends in invasive pneumococcal disease and pneumococcal serotypes over 7 decades. Clin Infect Dis. 2010;50(3):329-37. DOI: 10.1086/649872 PMID: 20047478

25. Wagenvoort GH, Sanders EA, Vlaminckx BJ, Elberse KE, de Melker HE, van der Ende A, et al. Invasive pneumococcal disease: Clinical outcomes and patient characteristics 2-6 years after introduction of 7-valent pneumococcal conjugate vaccine compared to the pre-vaccine period, the Netherlands. Vaccine. 2016;34(8):1077-85. DOI: 10.1016/j. vaccine.2015.12.066 PMID: 26778420

26. Rothman K, Greenland S. Chapter 15: Introduction to stratified analysis. In: Rothman K, Greenland S, editors. Modern epidemiology. 3rd ed. Philadelphia: Wolters Kluwer; 2008. p. 258-282.

27. Muenchhoff $M$, Goulder PJ. Sex differences in pediatric infectious diseases.J Infect Dis. 2014;209(Suppl 3):S120-6. DOI: 10.1093/infdis/jiu232 PMID: 24966192

28. Liptzin DR, Landau LI, Taussig LM. Sex and the lung: Observations, hypotheses, and future directions.Pediatr Pulmonol. 2015;50(12):1159-69. DOI: 10.1002/ppul.23178 PMID: 25906765

29. Voysey M, Barker CI, Snape MD, Kelly DF, Trück J, Pollard AJ. Sex-dependent immune responses to infant vaccination: an individual participant data meta-analysis of antibody and memory B cells.Vaccine. 2016;34(14):1657-64. DOI: 10.1016/j. vaccine.2016.02.036 PMID: 26920472

30. Jungers $P$, Chauveau P, Descamps-Latscha B, Labrunie $M$, Giraud E, Man NK, et al. Age and gender-related incidence of chronic renal failure in a French urban area: a prospective epidemiologic study. Nephrol Dial Transplant. 1996;11(8):15426. DOI: 10.1093/oxfordjournals.ndt.a027610 PMID: 8856208

31. Nuorti JP, Butler JC, Farley MM, Harrison LH, McGeer A, Kolczak MS, et al. Cigarette smoking and invasive pneumococcal disease. N Engl J Med. 2000;342(10):681-9. DOI: 10.1056/ NEJM200003093421002 PMID: 10706897

32. Inverarity D, Lamb K, Diggle M, Robertson C, Greenhalgh D, Mitchell TJ, et al. Death or survival from invasive pneumococcal disease in Scotland: associations with serogroups and multilocus sequence types. J Med Microbiol. 2011;6o(Pt 6):793-802. DOI: 10.1099/jmm.0.028803-o PMID: 21393453

33. Flasche S, Van Hoek AJ, Sheasby E, Waight P, Andrews $\mathrm{N}$, Sheppard C, et al. Effect of pneumococcal conjugate vaccination on serotype-specific carriage and invasive disease in England: a cross-sectional study. PLoS Med. 2011;8(4):e1001017. DOI: 10.1371/journal.pmed.1001017 PMID: 21483718

34. de Greeff SC, de Melker HE, Westerhof A, Schellekens JF, Mooi FR, van Boven M. Estimation of household transmission rates of pertussis and the effect of cocooning vaccination strategies on infant pertussis. Epidemiology. 2012;23(6):852-60. DOI: 10.1097/EDE.ob013e31826c2b9e PMID: 23018969

\section{License and copyright}

This is an open-access article distributed under the terms of the Creative Commons Attribution (CC BY 4.0) Licence. You may share and adapt the material, but must give appropriate credit to the source, provide a link to the licence, and indicate if changes were made.

This article is copyright of the authors, 2017. 